\title{
MENANTANG PARADIGMA MISI KRISTEN YANG BERSIFAT KOGNITIF-PROPOSISIONAL DENGAN MENGEMBANGKAN PENGETAHUAN HISTORIS MISI
}

\author{
Maraike Joanna Belle Bangun
}

\begin{abstract}
Mission, a basic facet of Christianity, has been deployed in many different ways. One strategy has been by means of violence, rooted as this approach has been in a cognitive-propositional mode of thinking. In this article, I show the importance of maintaining a historical understanding of mission, in order to challenge certain realizations of Christian mission driven by such a cognitive-propositional paradigm. This article appropriates aspects of George A. Lindbeck's thought, in order to explain the characteristics of the cognitive-propositional paradigm and its implications for Christian mission.
\end{abstract}

Keywords: Christian misison, cognitive-propositional, history of Christian mission, George A. Lindbeck.

\begin{abstract}
Abstrak
Misi sebagai bagian dari sifat dasar kekristenan telah diwujudkan melalui banyak cara. Salah satunya adalah dengan menggunakan medium kekerasan yang berakar pada cara berpikir kognitifproposisional. Melalui artikel ini saya ingin memperlihatkan pentingnya memiliki pengetahuan historis mengenai sejarah misi Kristen dalam menantang misi Kristen yang didorong oleh paradigma berpikir kognitif-proposisional. Artikel ini sepenuhnya menggunakan pemikiran George A. Lindbeck untuk menjelaskan karakteristik paradigma kognitif-proposisional dan implikasinya terhadap misi Kristen.
\end{abstract}

Kata-Kata Kunci: misi Kristen, kognitif-proposisional, sejarah misi Kristen, George A. Lindbeck. 


\section{Pendahuluan}

"This dimension of Christian faith is not an optional extra: Christianity is missionary by its very nature, or it denies its very raison d'être'.

Saya memulai makalah ini dengan mengutip pernyataan Bosch dalam Transforming Mission: Paradigm Shifts in Theology of Mission (2005) yang menyatakan sifat dasariah kekristenan adalah misionaris. Menurut Bosch sifat dasariah ini tidak bersifat opsional melainkan inheren di dalam kekristenan itu sendiri. Menanggalkannya dari kekristenan berarti mengkhianati tujuan utama kehadiran kekristenan. Hal senada juga ditegaskan oleh Bevans dan Schroeder dalam Constant in Context: A Theology of Mission for Today (2004). Bab pertama buku ini, "Missionary by Its Very Nature: Context and Church's Mission," menjelaskan bagaimana kitab Kisah Para Rasul memperlihatkan asal muasal gereja yang berakar dalam kesadarannya akan hakikat misionernya sehingga menjadi dasar alkitabiah bagi diktum yang terdapat dalam Ad Gentes (Decree on the Church's Missionary Activity, Vatican II) yang menyatakan gereja adalah "missionary by its very nature."2

Terkait sifat misionaris gereja ini, ide ini ternyata diwujudkan secara beragam di dalam sejarah kekristenan. Salah satunya adalah dengan menggunakan medium kekerasan. ${ }^{3}$ Pengalaman kekristenan pada abad pertengahan merupakan salah satu contohnya. Dana L. Robert dalam Christian Mission: How Christianity Became a World Religion (2009) mencatat,

${ }^{1}$ David J. Bosch, Transforming Mission: Paradigm Shifts in Theology of Mission (Maryknoll, New York: Orbis Books, 2005), 9.

2 Stephen B. Bevans dan Roger P. Schroeder, Constants in Context: A Theology of Mission for Today (Maryknoll, New York: Orbis Books, 2004), 30.

${ }^{3}$ Medium kekerasan dalam melaksanakan misi hanyalah salah satu wujud pelaksanaan misi. Tidak selalu sejarah misi Kristen dipenuhi dengan narasi kekerasan. Salah satu contohnya adalah kehadiran Bartholomeaeus Ziegenbalg (1682-1719) dan Heinrich Plütschau (1677-c.1746) di Tranquebar (salah satu daerah jajahan Kerajaan Denmark di bagian selatan India) pada 1706. Mereka justru mendapatkan penganiayaan dan dimasukkan ke dalam penjara oleh orang-orang Denmark yang bertugas di sana karena berusaha mengembangkan kehidupan orang Tamil. Mereka berhasil menerjemahkan Perjanjian Baru ke dalam bahasa Tamil, membangun sekolah-sekolah, dan memberikan layanan sosial kepada masyakarat. Lih. Dana L. Robert, "Introduction" dalam Converting Colonialism: Visons and Realities in Mission History, 1706-1914, peny. Dana L. Robert (Grand Rapids, M.I.: Wm. B. Eerdmans Publishing Company, 2008), 7-8. 
In the medieval unity of church and state, coercion became intertwined with mission in both theory and practice. The spiritual devotion of the early Crusaders was undeniable, and they made huge financial sacrifice. But their medieval version of Christianity confused evangelization with violent conquest and the slaughter of people unlike themselves. ${ }^{4}$

Menurut Robert penginjilan pada abad-abad pertengahan disertai juga dengan penaklukan yang kejam dan pembunuhan yang dipengaruhi oleh bangkitnya dunia kekristenan (christendom) dan budaya kekerasan yang dibawa oleh kaum Barbar di utara Eropa yang menjadi Kristen. ${ }^{5}$

Salah satu catatan tentang sejarah penyebaran kekristenan yang memperlihatkan perkawinan antara kekerasan dan misi Kristen terdapat dalam "A Violent Evangelism: The Political and Religious Conquest of the Americans" (1992) oleh Luis N. Rivera. Salah satu contoh yang diberikan Rivera adalah justifikasi yang diberikan oleh pemimpin agama Kristen untuk melakukan pembunuhan ketika berhadapan dengan mereka yang tidak mau "bertobat,"

For example, when dealing with gentiles, those who can hardly be expected to convert or abandon their sinful life. In that case, it would be without doubt holy and legitimate to kill them all, or at least, as many as would be considered necessary to achieve that aim. ${ }^{6}$

Catatan di atas memperlihatkan bagaimana bagaimana kekristenan bingung dalam menghadapi perbedaan sampai-sampai menempuh jalur kekerasan. Masih terdapat banyak buku yang dapat memperlihatkan lembaran hitam dari sejarah misi Kristen sehingga tidaklah mengherankan jika misi dan misionaris mendapatkan konotasi yang negatif. ${ }^{7}$

Jika dilihat dari perspektif poskolonialisme, misi merupakan salah satu komponen utama dalam kolonialisme dan imperialisme kultural yang dilaksanakan oleh para misionaris laki-laki dan perempuan pada abad ke-19 yang berusaha mencangkokkan gereja dan budaya mereka ketika pemberitaan Injil dilakukan. ${ }^{8}$ Perspektif ini

\footnotetext{
${ }^{4}$ Dana L. Robert, Chrisitan Mission: How Christianity Became a World Religion (U.K.: Wiley-Blackwell, 2009), 24.

${ }^{5}$ Ibid.

${ }^{6}$ Luis N. Rivera, A Violent Evangelism: The Political and Religious Conquest of the Americas (Louisville, Kentucky: Westminster/John Knox Press, 1992), 211.

${ }^{7}$ J. Andrew Kirk, What Is Mission: Theological Explorations (Minneapolis: Fortress Press, 2000), 22.

${ }^{8}$ Letty M. Russell, "Cultural Hermeneutics: A Postcolonial Look at Mission," Journal of Feminist Studies in Religion, Vol. 20, no. 1 (Spring 2004): 24.
} 
juga memperlihatkan bagaimana misi Kristen telah membuat Allah diasosiasikan dengan emas, kemuliaan, seksisme dan rasisme. ${ }^{9}$ Bahkan, misi pada akhir abad ke-19 memperlihatkan adanya ikatan yang intrinsik antara kekristenan dengan hegemoni kolonialisme. ${ }^{10}$ Oleh sebab itu tidaklah mengherankan jika kekristenan di banyak tempat dianggap sebagai agama Barat atau sebuah kebudayaan yang datang dari luar yang kemudian dipaksakan kepada orang-orang setempat.

Dengan demikian, tantangan misi Kristen masa kini adalah untuk tidak terjebak ke dalam semangat kekerasan seperti yang telah diperlihatkan oleh catatan-catatan sejarah misi Kristen. Kekerasan yang dimaksud bukan hanya kekerasan secara fisik tetapi juga kekerasan secara ideologis yang tanpa sadar dipegang oleh seseorang. Kekerasan ini adalah "any strong initiative or forceful action that reaches beyond normal dialogue, infringes upon the freedom of other(s), and imposes a solution or a situation upon others, at times against their desires". ${ }^{11}$ Definisi kekerasan ini memperlihatkan bahwa kekerasan juga terjadi ketika ada pemaksaan ide atau konsep pada pihak tertentu. Menurut saya, hal ini sangat mungkin terjadi jika seseorang memiliki paradigma misi yang bersifat kognitifproposisional yaitu, sebuah paradigma misi yang melihat kekristenan sebagai satu-satunya kebenaran yang absolut dan bersifat otoritatif mengatasi agama atau budaya apa pun.

Menurut saya tantangan di atas dapat dijawab ketika seseorang memiliki pengetahuan historis yang memadai tentang sejarah misi Kristen. Asvi Warman Adam, dalam pengantar yang ditulisnya untuk Berpikir Historis: Memetakan Masa Depan, Mengajarkan Masa Lalu (2006), mengatakan bahwa sejarah dapat mengajarkan budi pekerti dan sikap rendah hati sehingga kesalahan-kesalahan di masa lalu tidak perlu terulang kembali. ${ }^{12}$ Oleh sebab itu, argumentasi utama paper ini adalah pengetahuan historis mengenai sejarah misi Kristen akan menantang paradigma misi yang bersifat kognitif-proposisional sehingga misi Kristen yang dihadirkan memiliki semangat rendah hati

\footnotetext{
${ }^{9}$ Ibid., 29.

${ }^{10}$ Lamin Sanneh, Translating the Message: The Missionary Impact on Culture (Maryknoll, New York: Orbis Books, 2009), 5, 122. Meskipun demikian, Sanneh juga memperlihatkan bagaimana kekristenan yang justru hadir dalam bahasa-bahasa lokal telah memunculkan wajah kekristenan yang khas lokal yang justru menantang dan menolak model kekristenan Victoria/Barat yang pada mulanya, tanpa sadar maupun sadar, ingin diwujudkan oleh para misionaris $(5,211-213)$.

${ }^{11}$ Donald Senior dan Carroll Stuhlmueller, The Biblical Foundations for Mission (Maryknoll, New York: Orbis Books, 2003), 40-41.

12 Sam Wineburg, Berpikir Historis: Memetakan Masa Depan, Mengajarkan Masa Lalu (Jakarta: Yayasan Obor Indonesia, 2006), vii.
} 
yang berani (dalam istilah Bosch: bold humility). Usaha untuk mencapai tesis ini akan saya lakukan dengan menjelaskan pendekatan kognitifproposisional yang dijabarkan oleh Geoge A. Lindbeck untuk kemudian diperlihatkan implikasinya terhadap misi Kristen. Selanjutnya saya akan memperlihatkan bagaimana pengetahuan tentang sejarah misi Kristen dapat menjadi semacam "penawar" agar seseorang tidak terjebak dalam model misi yang didorong oleh paradigma kognitif-proposisional.

\section{Paradigma Kognitif-Proposisional dan Implikasinya terhadap Misi Kristen}

Dalam bukunya, The Nature of Doctrine (1984), George A. Lindbeck mengulas beberapa teori tentang doktrin untuk menemukan sebuah pendekatan yang dapat mengatasi masalah doktrinal dalam gerakan ekumenikal. ${ }^{13}$ Lindbeck membagi teori-teori doktrin ke dalam tiga jenis, kognitif-proposisional (akan dijelaskan lebih lanjut), ekspresif-pengalaman (agama dilihat sebagai simbolsimbol perasaan, sikap atau orientasi eksistensial yang noninformatif dan nondiskursif, ${ }^{14}$ dan terakhir linguistik-kultural (agama dilihat sebagai sebuah kerangka atau medium budaya/bahasa yang membentuk seluruh kehidupan dan pemikiran. ${ }^{15}$ Kognitifproposisional adalah sebuah pendekatan yang menekankan dimensi kognitif dari agama yang melihat fungsi doktrin gereja sebagai proposisi atau klaim kebenaran tentang obyek realitas. ${ }^{16}$ Dalam tulisan ini, saya akan memperlihatkan implikasi pendekatan kognitifproposisional terhadap misi Kristen.

Saya mengidentifikasi beberapa karakteristik yang dimiliki oleh pendekatan ini yang memiliki implikasi terhadap paradigma dan praktek misi Kristen. Karakteristik pertama melihat doktrin gereja/agama sebagai penentu kebenaran mengenai realitas. Karakteristik ini menekankan "the cognitive aspects of religion and stresses the ways in which church doctrines function as informative propositions or truth claims about objective realities". ${ }^{17}$ Agama dilihat sama seperti filsafat atau ilmu pengetahuan, dalam pengertian klasik,

13 George Lindbeck, The Nature of Doctrine: Religions and Theology In a Postliberal Age (London: SPCK, 1984), 8.

14 Ibid., 16.

15 Ibid., 33.

16 Ibid., 16.

17 Ibid. 
yang dapat menjelaskan realitas. ${ }^{18}$ Merujuk pada karakteristik pertama ini, seseorang akan melihat kekristenan sebagai sumber penjelasan obyektif atas realitas sehingga paradigma misi yang mungkin berkembang adalah semangat bahwa kekristenan adalah jawaban yang valid atas realitas. Salah satu slogan yang dekat dengan karakteristik ini adalah "Jesus is the Answer" terhadap segala permasalahan hidup manusia.

Karakteristik kedua adalah doktrin gereja/agama adalah benar dan tidak mungkin salah. Demikian penjelasan Lindbeck, "For a propositionalist, if a doctrine is once true, it is always true, and if it is once false, it is always false." ${ }^{\prime 19}$ Berangkat dari pemahaman ini tidak memungkinkan terjadi sebuah harmonisasi antara dua pandangan yang berbeda tanpa melepaskan salah satu pandangan lainnya. ${ }^{20}$ Demikian catatan Lindbeck,

Agreement can be reached only if one or both side abandon their earlier positions. Thus, on this view, doctrinal reconciliation without capitulation is impossible because there is no significant sense in which the meaning of a doctrine can change while remaining the same. ${ }^{21}$

Catatan di atas menegaskan bahwa perbedaan tidak mungkin diperdamaikan kecuali salah satu pihak melepaskan identitasnya dan mengambil identitas pihak lain. Model misi yang menggunakan paradigma misi ini akan mengalami kesulitan untuk duduk bersama dan berdialog, terlebih lagi berbagi hidup dengan mereka yang memiliki pemahaman yang berbeda. Walaupun dialog dilakukan, tujuannya adalah untuk mengubah pandangan pihak lain agar menjadi sama dengan kita dan bukan belajar dari pihak lain dalam rangka merayakan kemajemukan yang diizinkan oleh Allah.

Karakteristike ketiga dari pendekatan ini berhubungan dengan otoritas sebuah pengajaran. Demikian ulasan Lindbeck, "The conceptual difficulties involved in traditioinal propositional notions of authoritative teaching have contributed to discrediting the whole doctrinal enterprise."22 Adanya otoritas yang diberikan kepada sebuah pengajaran justru mendiskreditkan doktrin-doktrin lain yang ada. Otoritas ini kemudian digunakan untuk melegitimasi hal-hal yang kaku, tidak menyentuh hal-hal yang bersifat esensi dan kemudian menjadi kontra-produktif dengan alasan:

\footnotetext{
18 Ibid.

19 Ibid.

20 Ibid.

${ }^{21}$ Ibid., 16-17.

22 Ibid., 78.
} 
First, propositionalism makes it difficult to understand how new doctrines can develop in the course of time, and how old ones can be forgotten or become peripheral. Second, propositionalist accounts of how old doctrines can be reinterpreted to fit new circumstances are unconvincing: they have difficulty in distinguishing between what changes and what remains the same. Third, they do not deal adequately with the specifically ecumenical problematic: how is it possible for doctrines that once contradicted each other to be reconciled and yet retain their identity? ${ }^{23}$

Dengan demikian, praktik misi yang dipengaruhi oleh karakteristik ini akan menjadi tidak relevan ketika diterapkan di dalam masyarakat yang majemuk karena hakikatnya yang menolak perbedaan. Misi Kristen yang hadir dalam bentuk dialog dengan tujuan saling memperkaya dan menemukan karya keselamatan Allah akan dianggap mustahil. Reinterpretasi terhadap sebuah doktrin agar sesuai dengan sebuah konteks baru pun dipertanyakan. Di sini hanya ada satu wajah misi, yaitu otoritatif dan absolut.

Karakteristik keempat adalah kecenderungan untuk menjadi sangat literalistik. Hal ini didorong oleh keinginan untuk mempertahankan identitas dengan "reproducing as literalistically as possible the words and actions of the past". ${ }^{24}$ Mereka yang Protestan akan menjadi biblis dan yang Katolik akan menjadi tradisionalis. ${ }^{25}$ Paul F. Knitter mengkategorikan pendekatan kognitif-proposisional sebagai "universal truth-claims" atau yang dikenal sebagai "metanarratives." 26 Orang Kristen yang menganut paradigma berpikir ini akan melihat Alkitab sebagai pemberian Allah yang mengandung perkataan yang benar sehingga jika semua dituruti secara harafiah segalanya akan berjalan dengan baik. ${ }^{27}$ Dengan kata lain, model pendekatan ini menganggap bahwa caranya atau doktrinnya adalah satu-satunya kebenaran dan yang lain harus mengikuti kebenaran tersebut. Alkitab dihayati sebagai otoritas tertinggi yang berfungsi sebagai alat legitimasi dan didalami secara hurufiah.

Praktek misi Kristen yang dilandasi oleh karakteristik ini pada abad-abad pertengahan yaitu memegang pedang di tangan kanan dan Alkitab di tangan kiri dalam memperluas kekristenan. Pada masa kini mungkin tidak sama secara fisik, tetapi pada tataran ideologis

23 Ibid.

24 Ibid., 79.

25 Ibid., 78.

${ }^{26}$ Paul F. Knitter, Introducing Theologies of Religions (Maryknoll, New York: Orbis Books, 2002), 177.

${ }^{27}$ Ibid., 179. 
prinsipnya adalah “Thus says the Lord, let it be." Teks-teks Alkitab akan dibaca dan dipahami sebagaimana tertulis tanpa memperhatikan lokasi sosial penulis dan komunitas yang dituju. Dengan demikian teks-teks yang dianggap bersifat misioner seperti Matius 28:19-22 akan dibaca sebagai sebuah perintah mutlak tanpa mempertimbangkan tema utama Injil Matius, lokasi sosial, komunitas Matius dan situasi kontemporer di masa kini.

Terakbir, Lindbeck menyinggung unsur unsurpassibility atau sebuah keadaan di mana satu agama atau doktrin tidak mungkin tertandingi oleh yang lain. Karakteristik ini memperlihatkan aspek superioritas sebuah agama. Kategori yang digunakan untuk menguji sebuah agama atau doktrin adalah kategori benar atau salah. Agama yang paling final adalah agama yang harus bebas dari segala bentuk kesalahan agar tidak tertandingi. ${ }^{28}$ Lindbeck mengatakan, "This propositional inerrancy has usually been atributed in Christianity to the original 'deposit of faith,' though it has also been atributed to Scripture and de fide church doctrines." 29

Model misi Kristen yang memiliki karakteristik ini akan menempatkan dirinya lebih tinggi dari agama apa pun, juga atas budaya. Agama lain akan dianggap tidak sempurna dan salah. Hal yang sama juga berlaku atas budaya yang tidak tersentuh nilai-nilai kristiani. Budaya tersebut, jika tidak dapat dieksploitasi akan dihancurkan ${ }^{30}$ Bosch juga memperlihatkan bahwa kekristenan yang menggunakan pendekatan ini ditolak karena kekristenan dianggap lebih rasional daripada ilmu pengetahuan dan berfungsi sebagai peraturan bagi masyarakat. ${ }^{31}$

Berdasarkan pemaparan karakteristik pendekatan kognitif proposisionalis, dapat disimpulkan beberapa karakteristik khasnya, (1) Kekristenan dapat menjelaskan realitas secara objektif, (2) Ajaran kekristenan adalah benar, selamanya benar dan tidak mungkin salah, (3) Kekristenan adalah otoritas tertinggi, (4) Alkitab ditafsirkan dan dihayati secara hurufiah, dan (5) Kekristenan tidak tertandingi oleh agama lain atau superior terhadap agama dan budaya lain. Jika cara berpikir kognitif-proposisional tetap dipertahankan, baik secara sadar atau tidak, maka wajah misi Kristen masa kini akan tetap sama dengan misi pada abad ke-19 seperti yang dipaparkan Letty Russell,

The early combination of the imperialist, patriarchal social structures of the Greco-Roman empire with church structures gave the church a mandate for

\footnotetext{
${ }^{28}$ Lindbeck, The Nature of Doctrine, 49.

${ }^{29}$ Ibid.

${ }^{30}$ Knitter, Introducing Theologies of Religions, 177.

31 Bosch, Transforming Mission, 352.
} 
mission that combined with European imperialism in the ninteenth century. In the twenty-first century it is no longer credible to think of mission from a Euro-American perspective of "crossing salt water" to heathen lands, because we live in a global society where the need for witness to God's justice and care is in each and every place. ${ }^{32}$

Russell memperlihatkan bahwa model misi yang imperialis, patriarkhis, dan dikombinasikan dengan imperialisme Eropa abad ke19 tidak lagi kredibel pada masa kini. Praktek fisiknya mungkin tidak sama tetapi semangatnya tetap ada di dalam praktek misi Kristen ketika paradigma misi Kristen yang bersifat kognitif-proposisional tetap dipertahankan. Oleh sebab itu, haruslah ditemukan sebuah cara untuk meruntuhkan paradigma misi yang cenderung bersifat absolut, imperialistik dan tidak relevan ini di tengah masyarakat global yang plural yang sebenarnya membutuhkan kehadiran kekristenan sebagai saksi keadilan dan kepedulian Allah.

\section{Menantang Paradigma Misi Kristen yang Bersifat Kognitif-Proposisional}

Berdasarkan pemaparan di atas, tentulah paradigma misi yang bersifat kognitif-proposisional tidak diharapkan untuk terwujud. Tantangan misi Kristen masa kini adalah apa yang dapat dilakukan untuk meruntuhkan paradigma misi Kristen yang melihat kekristenan sebagai "universal truth-claim." 33 Menurut saya sejarah memainkan peran yang penting untuk meruntuhkan paradigma misi ini. Timothy Yates menyatakan bahwa sejarah adalah aspek yang penting ketika seseorang mempelajari teori dan praktik misi Kristen. ${ }^{34}$ Studi tentang teori dan praktik misi harus memberikan perhatian terhadap latar belakang historis, terutama pada pengaruh atau dinamika relasi antara lokasi sosial dengan pesan atau si pembawa pesan dalam sebuah masyarakat tertentu. ${ }^{35}$ Menurut saya proses ini penting bukan hanya bagi mereka yang mendalami bidang studi Misiologi. Proses ini sudah seharusnya menjadi bagian dari proses pembinaan warga jemaat.

Tidak hanya itu saja, Yates pun menambahkan:

32 Russell, "Cultural Hermeneutics,” 33.

${ }^{33}$ Knitter, Introducing Theologies of Religions, 177.

${ }^{34}$ Timothy Yates, Christian Mission in the Twentieth Century (Cambridge: University Press, 1994), 4.

35 Ibid., 5. 
. . missiology is at its best when history and theology are beld in tension and there is a continuing oscillation between historical context and Christian input, so that the analysis of the form in which the gospel is expressed, the theory of the mission, is related firmly to the setting. ${ }^{36}$

Dengan kata lain, Yates ingin menegaskan bahwa bidang studi Misiologi akan menjadi maksimal ketika sejarah dan teologi berada dalam ketegangan dan proses bolak-balik antara konteks sejarah dan kekristenan. Hanya dengan demikian, analisis terhadap teori dan praktik misi tidak tercabut dari konteksnya dan akan menjadi jelas. Yates mengimplikasikan bahwa sebuah teori atau paradigma misi tidak terjadi di ruang yang kosong; teori atau paradigma misi tersebut pasti memiliki lokasi sosial yang harus diperhatikan dengan baik. Hal ini penting bagi warga jemaat atau gereja yang memiliki kerinduan untuk terlibat dalam misi Allah. Paradigma misi yang dimiliki oleh gereja harus ditelisik akar sejarahnya dan konteksnya pada saat itu. Sesudah itulah gereja dapat mengenal secara utuh pemahaman misi yang dimilikinya untuk kemudian dipertimbangkan apakah ia kompatibel dengan situasi kontemporer yang dihadapi gereja.

Jehu J. Hanciles dalam "New Wine in Old Wineskins: Critical Reflection on Writing and Teaching a Global Christian History" (2006) menekankan aspek yang sama seperti Yates. Menurutnya,

... it is important to remember that the past is the depository of the human experience, and that history - at least knowledge of the past - provides the foundation of every sphere of learning and professional training. ${ }^{3}$

Ia juga menyatakan,

The far more crucial consideration is that poor knowledge of history or inattentiveness to the rich vistas of the human past impoverishes our intellectual training, limits our vision of the remarkable richness and diversity of human existence, and potentially undermines our understanding of divine actions and intentions. ${ }^{38}$

Hanciles menyatakan bahwa sejarah merupakan tempat penyimpanan pengalaman manusia yang menyediakan fondasi bagi pembelajaran dan pelatihan. Kurangnya pengetahuan dan ketidakpedulian akan

36 Ibid.

37 Jehu J. Hanciles, "New Wine in Old Wineskins: Critical Reflections on Writing and Teaching a Global Christian History" Missiology: An International Review, Vol. XXXIV, no. 3 (July 2006): 362.

38 Ibid. 
sejarah justru memiskinkan intelektualitas seseorang. Hal ini juga membatasi jangkauan pandangan seseorang dan membuat seseorang tidak mampu menghargai kemajemukan. Sejarah membantu kita untuk memiliki kemampuan mental yang tidak ternilai yang dinamakan penilaian. ${ }^{39}$

Oleh sebab itu, penting sekali untuk memiliki pengetahuan historis akan sejarah misi Kristen demi memperluas khasanah berpikir terkait teori dan praktik misi Kristen sehingga kita tidak akan terjebak dalam model berpikir kognitif-proposisional dan dapat membangun paradigma misi Kristen yang lebih maju (advance). Saya sepakat dengan pendapat Hanciles yang mengatakan bahwa kekristenan adalah sebuah iman yang bersifat historis sehingga tidak mungkin bagi teologi ataupun misiologi untuk tidak melakukan pendalaman sejarah,

In effect, netiher theology nor missiology can ignore serious historical study without paying a heavy intellectual cost. Christianity is a historical faith perhaps the most historical of faiths - and the exceptional diversity of Christian mission in indispendsable for a full understanding of its impact in the world and its global presence. ${ }^{40}$

Usaha untuk memperdalam pengetahuan historis akan sejarah misi dapat dilakukan dengan membaca buku-buku sejarah misi Kristen. Salah satunya adalah buku karya David J. Bosch yang dengan cermat meneliti adanya pergeseran paradigma misi Kristen sejak berkembangnya kekristenan mula-mula hingga masa kini, yang dibagi ke dalam lima periode sejarah kekristenan. ${ }^{41}$ Bosch menolong pembacanya dengan mendaftarkan enam krisis global yang telah menjadi konteks besar bagi pergeseran paradigma tersebut. ${ }^{42}$ Menurut saya, dengan membaca buku seperti ini seseorang akan dibantu untuk memahami bahwa paradigma misi Kristen tidak ada yang tunggal dan absolut. Perpektif historis seperti ini akan membuat seseorang meninggalkan paradigma misi yang bersifat kognitif-proposisional.

Dengan membaca buku ini, konsep berpikir seseorang akan berbenturan dengan kenyataan bahwa paradigma misi Kristen terus bergeser seiring berjalannya waktu. Kekristenan harus berubah. Seseorang pada akhirnya, ketika berhadapan dengan sejarah misi Kristen, akan menyadari bahwa apa yang dianggap benar pun harus menyesuaikan diri dengan perubahan konteks. Dengan demikian

\footnotetext{
${ }^{39}$ Wineburg, Berpikir Historis, 5.

${ }^{40}$ Hanciles, New Wine in Old Wineskins, 362.

${ }^{41}$ Bosch, Transforming Mission, 187-188.

42 Ibid., 3.
} 
karakteristik kedua dari paradigma misi yang bersifat kognitifproposisional yang mengatakan bahwa kekristenan mutlak benar dan tidak akan berubah menjadi luruh.

Bosch juga menggunakan pendekatan sejarah dalam membaca teks Alkitab. Menurutnya, sejarah dan teologi kekristenan mula-mula adalah "sejarah misi" dan "teologi misi". "33 Bosch menyatakan bahwa,

It is important to note that the New Testament authors also differed from one another, not least in their understanding of mission. . . We should, however, not be surprised if the New Testament does not reflect a uniform view of mission but, rather a variety of "theologies of mission. ${ }^{44}$

Kenyataan akan keberagaman teologi misi di dalam Alkitab diperlihatkan oleh Bosch dengan mengulas paradigma misi yang berkembang di antara orang Kristen mula-mula Matius, Lukas dan Paulus. ${ }^{45}$ Dengan demikian, teks-teks yang selama ini dianggap sebagai teks misi dan dibaca dan diterapkan secara hurufiah akan berjumpa dengan interpretasi yang lebih utuh karena mempertimbangkan lokasi sosial setiap surat atau Injil. Dengan membaca buku seseorang yang biasa membaca Alkitab secara literalistik akan ditantang untuk melihat Alkitab dari perspektif yang berbeda.

Buku sejarah perjalanan misi Kristen lainnya yang akan membuka wawasan berpikir seseorang yang berpikir secara kognitifproposisional adalah Constant in Context: A Theology of Mission for Today (2004) yang ditulis oleh Stephen B. Bevands dan Roger P. Schroeder. Argumentasi utama buku ini adalah:

Christian mission is both anchored in fidelity to the past and challenged to fidelity in the present. It must preserve, defend and proclaim the constants of the church's traditions; at the same time it must respond creatively and boldly to the contexts in which it finds itself. Christian history is a story of the church mission. It is, to borrow the eloquent phrase of Harvie Conn, a story of the encounter of Eternal Word with changing worlds. As we express it in this book, it is a story of constans in contexts. ${ }^{46}$

Argumentasi di atas ingin memperlihatkan bagaimana misi Kristen mengalami perubahan seturut dengan berubahnya konteks di mana kekristenan itu hadir. Akan tetapi, menurut sejarah, misi Kristen tetap

\footnotetext{
43 Ibid., 15.

44 Ibid., 17.

45 Ibid., 56-178.

46 Bevans dan Schroeder, Constant in Context, 1.
} 
setia kepada yang enam aspek konstan dalam kekristenan, yaitu Kristologi, Eklesiologi, Eskatologi, Soteriologi, Antropologi dan Kebudayaan. ${ }^{47}$ Bevans dan Schroeder memanfaatkan tiga tipologi teologi yang diusulkan oleh Justo L. Gonzales dan Dorothe Sölle untuk memudahkan pembacanya memahami perubahan-perubahan praktek misi Kristen di dalam sejarah kekristenan.

Berangkat dari penelusuran tipologi-tipologi misi Kristen di dalam sejarah misi Kristen, Bevans dan Schroeder kemudian mengusulkan semangat yang seharusnya dihadirkan oleh misi Kristen,

And just as the triune God's missionary presence in creation is never about imposition but always about persuasion and freedom-respecting love, mission can no longer proceed in ways that neglect the freedom and dignity of human beings. ${ }^{48}$

Semangatnya bukan lagi memaksakan kekristenan tetapi berupa undangan yang disertai hormat dan kasih yang terbuka terhadap penolakan. Oleh sebab itu, setelah melakukan penelusuran terhadap sejarah misi Kristen, tidaklah mengherankan kalau Bevans menyimpulkan bahwa misi sebagai keterlibatan dalam misi Allah trinitas hanya dapat dilakukan dalam melalui dialog yang disertai dengan kerendahan hati bagi konteks masa kini. ${ }^{49}$

Dua buku di atas hanyalah dua di antara buku-buku yang membahas sejarah perkembangan misi Kristen. Buku-buku seperti ini akan memperluas pengetahuan historis seseorang mengenai sejarah misi Kristen sehingga paradigma misi yang bersifat proposisional kognitif dapat diruntuhkan. Buku-buku sejarah misi Kristen akan menolong kita untuk berkaca dari masa lalu sehingga pada masa kini kita akan lebih arif dalam membuat penilaian dan keputusan yang akan akan mempengaruhi masa depan.

\section{Kesimpulan}

"But there is one other thing for historical thought to do: namely to create this progress itself. For progress is not a mere fact to be discovered by historical thinking: it is only through historical thinking that it comes about at all." 50

47 Ibid., 34.

48 Ibid., 348.

49 Ibid.

${ }^{50}$ R. G. Collingwood, The Idea of History (New York: Oxford University Press, 1956), 333. 
Pada bagian akhir karya Collingwood, The Idea of History (1956), ia menyatakan kalau kemajuan hanya mungkin lahir ketika seseorang atau sebuah masyarakat mampu berpikir secara historis. Contoh yang diberikan oleh Collingwood adalah perkembangan (advancement) yang dihasilkan oleh Einstein atas teori Newton hanya terjadi ketika Einstein mengenal seluk beluk teori Newton, termasuk kekuatan dan kegagalan teori ini ${ }^{51}$. Menurut Collingwood Newton hidup di dalam Einstein sama seperti sejarah terus hidup di dalam pikiran seorang sejarawan yang kemudian di atas sejarah tersebut perkembangan dibangun. ${ }^{52}$

Maka benarlah apa yang dinyatakan oleh Lesslie Newbigin tentang pentingnya memahami sejarah misi, "Any attempt to deal with the present without awareness of what has gone before can only lead to distorted vision and false judgment." ${ }^{53}$ Ketika seseorang memiliki pengetahuan historis tentang sejarah misi Kristen maka ia dapat membangun sebuah paradigma misi Kristen yang tidak ahistoris tetapi kontemporer dan setia pada core value misi Allah. Dengan demikian, misi Kristen pada masa kini tidak akan terjebak dalam paradigma misi yang bersifat kognitif-proposisional. Semoga ini proses ini akan menghadirkan wajah misi Kristen yang lebih rendah hati dibandingkan praktek misi abad-abad pertengahan yang kurang lebih sejalan dengan pemikiran Bosch seperti yang dikutip oleh Saayman:

... . we regard our involvement in dialogue and mission as an adventure, are prepared to take risks, and are anticipating surprises as the Spirit guides us into fuller understanding. This is not opting for agnosticism, but for humiliy. It is, however, a bold humility - or a humble boldness. We know only in part, but we do know. And we believe that the faith we profess is both true and just, and should be proclaimed. We do this, however, not as judges or lawyers, but as witnesses; not as soldiers, but as envoys of peace; not as high-pressure salespersons, but as ambassadors of the Servant Lord. ${ }^{54}$

Wajah misi Kristen yang memiliki wawasan historis mengenai sejarah misi Kristen tidak seperti hakim, tentara, atau penjual yang suka

\footnotetext{
51 Ibid.

52 Ibid., 334.

${ }^{53}$ Lesslie Newbigin, The Open Secret: An Introduction to the Theology of Mission (Grand Rapids, Michigan: William B. Eerdmans Publishing Company, 1995), 3.

54 Willem Saayman dan Klippies Kritzinger, peny. Mission in Bold Humility: David Bosch's Work Considered (Maryknoll, New York: Orbis Books, 1996), v.
} 
memaksa. Wajah misi Kristen yang belajar dan dibangun atas dasar sejarah misi Kristen itu adalah seperti saksi, pendukung perdamaian dan duta besar Tuhan yang Melayani.

\section{Tentang Penulis}

Maraike Joanna Belle Bangun adalah lulusan STT Jakarta (S.si [Teol.] 2008 dan M. Th. 2015) yang mendalami bidang studi Pendidikan Kristiani dan Misiologi. Penelitian tesis M. Th. difokuskan pada narasi para migran asal Indonesia dan Filipina dan implikasinya pada jati diri misional gereja migran Malaysia. Ia telah menerjemahkan beberapa buku ke dalam Bahasa Indonesia, antara lain Living the Resurrection Everyday (BPK Gunung Mulia, 2009), delapan bab dari Sexual Offending and Restoration (BPK Gunung Mulia, 2009), dan A Multitude of Blessing (akan diterbitkan oleh BPK Gunung Mulia). Mulai September 2015-Januari 2016 akan mengajar di STT GKS Lewa, Sumba sebagai bagian dari program STT Jakarta Mengajar. Ia adalah anggota jemaat Gereja Kristen Kemah Daud (GKKD) Jakarta dan pernah melayani selama 5 tahun di Covenant Sanctuary, Sandakan, Sabah, Malaysia. 


\section{Daftar Pustaka}

Bevans, Stephen B. dan Roger P. Schroeder, Constants in Context: A Theology of Mission for Today. Maryknoll, New York: Orbis Books, 2004.

Bosch, David J. Transforming Mission: Paradigm Shifts in Theology of Mission. Maryknoll, New York: Orbis Books, 2005.

Collingwood, R. G. The Idea of History. New York: Oxford University Press, 1956.

Hanciles, Jehu J. "New Wine in Old Wineskins: Critical Reflections on Writing and Teaching a Global Christian History," Missioly: An International Review, Vol. XXXIV, no. 3 (July 2006): 361-382.

Kirk, J. Andrew. What is Mission: Theological Explorations. Minneapolis: Fortress Press, 2000.

Knitter, Paul F. Introducing Theologies of Religions. Maryknoll, New York: Orbis Books, 2002.

Lindbeck, George. The Nature of Doctrine: Religions and Theology in a Postliberal Age. London: SPCK, 1984.

Newbigin, Lesslie. The Open Secret: An Introduction to the Theology of Mission. Grand Rapids, Michigan: William B. Eerdmans Publishing Company, 1995.

Rivera, Luis N. A Violent Evangelism: The Political and Religious Conquest of the Americas. Louisville, Kentucky: Westminster/John Knox Press, 1992.

Robert, Dana L. Chrisitan Mission: How Christianity Became a World Religion. U.K.: Wiley-Blackwell, 2009.

, Dana L. "Introduction." Dalam Converting Colonialism: Visons and Realities in Mission History, 1706-1914, peny. Dana

L. Robert 1-20. Grand Rapids, Michigan: Wm. B. Eerdmans Publishing Company, 2008.

Russell, Letty M. "Cultural Hermeneutics: A Postcolonial Look at Mission," Journal of Feminist Studies in Religion, Vol. 20, no. 1 (Spring 2004): 23-40.

Saayman, Willem dan Klippies Kritzinger, peny. Mission in Bold Humility: David Bosch's Work Considered. Maryknoll, New York: Orbis Books, 1996.

Sanneh, Lamin. Translating the Message: The Missionary Impact on Culture (Second Edition Revised and Expanded). Maryknoll, New York: Orbis Books, 2009.

Senior, Donald dan Carroll Stuhlmueller, The Biblical Foundations for Mission. Maryknoll, New York: Orbis Books, 2003. 
Wineburg, Sam. Berpikir Historis: Memetakan Masa Depan, Mengajarkan Masa Lalu. Jakarta: Yayasan Obor Indonesia, 2006.

Yates, Timothy, Christian Mission in the Twentieth Century. Cambridge: University Press, 1994. 